\title{
CAN THE PRIVATE NATURE RESERVES CONTRIBUTE TO THE CONSERVATION OF SOUTHERN AFRICAN WILDLIFE?
}

\author{
P J LE ROUX \\ Director of Nature Conservation \\ The Provincial Administration of the Orange Free State \\ P O Box 517 \\ Bloemfontein \\ 9300
}

The basic question to which I apply myself in this paper is: Can a private nature reserve make a worthwhile contribution to the national conservation effort? To my mind, and I must emphasize from the start that the views expressed in this paper are wholly my own and not the official view of any conservation authority, the answer can at best be a severely qualified affirmative. Affirmative, because of the fact that any positive step, however small or hesitant, must be considered a contribution to the cause of conservation. Qualified, mainly because of the fact that permanency of any private conservation effort is strictly limitea by a number of factors, many of which may at one stage or another be beyond the control of the owner of the land.

Before looking at the question in detail, let us first consider the definition of a private nature reserve. A private nature reserve is an area of land in private ownership whereon the natural environment is preserved and managed to retain its essential character, and which enjoys some form of legal recognition.

The first variable to consider, not specified in the definition, is that of size. It would be trite to say that a private nature reserve should be as large as possible, and it would be also more or less meaningless. Perhaps it would be better to say that the size must be suited to the environment to be protected. If the intention is to preserve a particular stand of rare or outstanding plants, the size may be of the order of a few hectares. Should the purpose of the reserve be to preserve a representative sample of what we know as a veld type, a thousand hectares may be too small.

In the definition it is implied that the private nature reserve or at least part thereof, must be in a "natural" state. Unless the owner of the land is in the happy position of being able to let such land remain unused in the normally accepted sense, it is more usual that some form of produce from the land is expected. In the case of a stock farm, much of such produce could be obtained from land in a "natural" state, but if crops are grown, the natural environment will be disturbed or destroyed to 
some degree. Perhaps it would be most useful to insist that the whole of the area of the reserve must consist of land with vegetation in an advanced stage of succession. If the land is then supposed to be a productive unit, it follows that either the nature reserve must be only part of such a land unit, or some form of farming activity must be tolerated within the boundaries of the private nature reserve. If the latter concept is accepted, it must be made clear that such activity should not be detrimental to, or destructive of, the natural environment in any significant way, or it would nullify the basic principle of the private nature reserve.

A further aspect to be considered when a private nature reserve is created, is whether the natural environment is to include animal secondary producers to any extent, and if so, which animals should or could be tolerated or encouraged. Should only carrying capacity be considered in the determination of stocking rates and species to be used, or should the further restriction of only allowing animals known to have occurred in the geographical region be adhered to? Should only indigenous animals be tolerated or is there room for domestics or exotics filling an unoccupied niche?

Perhaps the one most important factor in any system of private nature reserves is the landowner himself. Is a love of nature an acquired trait, or is it a basic but not universal component of human nature? Is it reasonable to expect the average owner of land to make such a contribution to the conservation effort? Can a private nature reserve be shown to be a practical and economical use of a farming unit? Surely it would be a great boost to the idea if a landowner can be convinced that a private nature reserve need not be merely a luxury or a doubtful cultural asset but a productive method of land use.

It may be possible to get a few answers to these vexing questions if we look at the matter from a different angle. Instead of trying to define a private nature reserve, let us rather try and define the possible function which an ephemeral reserve can fulfil. In other words let us take a look at the need for such reserves, and then at the way in which one should go about satisfying that need.

The basic aim of any national system of nature reserves or parks, is to maintain in a natural state adequately representative samples of the country's natural environment, fauna and flora, for the benefit of the people for all time. Perpetuity is only a relative concept, but the closest approximation would be to vest ownership of such reserves in the State itself, or in other words, the people of the country. Without people, conservation becomes meaningless.

Any reserved area not in public ownership suffers from two fundamental shortcomings in the basic reserve concept. In the first place, it can usually be functional only for the period of the owner's life-span, and in many cases not even for that long, unless special legal precautions are taken. These legal restrictions are not generally very popular with land 
owners as they tend to be detrimental to his capital investment in the land. Secondly, the facilities of such a reserve are not normally or freely accessible to the general public, largely because of the additional cost and bother involved when facilities for such access have to be provided and maintained. It would seem, therefore, that reserves which are in private ownership, will have to make a significant contribution in the short term, if they are to be considered useful to the overall conservation effort. If such a role can be found for them, then surely their creation must be stimulated and encouraged, and their existence safeguarded in every possible way. The following is one man's ideas, not neccesarily exhaustive, of the possible contribution which may be made by private nature reserves:

(a) preservation of locally spectacular landscapes, plant associations, aggregations of birds or smaller terrestrial animals;

(b) preservation of a significant sample of the natural plant and animal species occurring in an identifiable biotic region;

(c) preservation of breeding nuclei of rare or sought-after animals thus relieving pressure on state reserves to maintain maximum numbers to satisfy the demand for such animals;

(d) supplying suitable resting, breeding and feeding places for migratory birds;

(e) maintaining reservoirs of much-exploited species of especially game birds to repopulate surrounding areas; and

(f) creating visual and factual evidence that the healthy natural environment can be tolerated, utilized and incorporated in a diversified farming enterprise.

In view of the still all too widespread abuse and spoilation of our land in the guise of farming, the last mentioned function may perhaps be the most important, but for the same reason may be the most difficult to fulfil.

From the fore-going it should be clear that there is room, for a system of private nature reserves in our conservation effort. Such a system can, however, at best be complementary to, and never a substitute for, a comprehensive, integrated, and fully adequate system of state reserves, whatever appellation these may bear. If such a view be accepted, it remains to be seen how their creation can be stimulated and how their development or use may be effectively controlled to ensure obtaining the desired results. As conservation is primarily the function of the state, it follows that the most effective and alluring incentive for the creation of private nature reserves would be some form of state concession to the landowner concerned, in other words, an offer the owner would not like to refuse. This is, however, a powerful tool which can easily become a double-edged sword, and as a result has to be employed with the utmost circumspection. Unless the objective is well-defined and kept clearly in 
mind, concessions may be made to unworthy causes at great expense to the taxpayer and of value only to the landowner and not to the conservation cause. Such a requirement places an extremely heavy burden of responsibility on the conservation executive and is probably the reason why only token measures have been taken in the past. A good example of the possible pitfalls which have to be avoided is the matter of fencing subsidies - a hardy perennial at congresses and such meetings. While it would be perfectly proper to my mind to subsidise the fencing of a particularly important tract of land, it can never be considered as a general contribution to the furtherance of, for example, game farming. The latter concept has so far defied properly strict definition and it follows that any general measure supporting it, would be open to some degree of abuse.

The only generality of significant state contribution to the creation of private nature reserves should be that each case be judged on its own merits, and that the contribution of the state bear relation to the contribution the private nature reserve can make to the national conservation effort. Such contribution can range all the way from granting greater freedom to the owner to manage wildlife affairs on his land, to the acquisition of servitude rights over any part of the natural environment. Naturally it would stop short of outright purchase, but could include payments for indemnity, subsidies and the like. The owner of the land, on the other hand, would have to be contractually bound to observe the sanctity of measures to ensure the efficacy of the private nature reserve, again viewed in the overall conservation context. Such contract would of course also have to be tailored to the needs and values of the particular reserve or conservation facet represented.

In summary and conclusion then, I submit that a system of private nature reserves can be of great benefit as addition to a national conservation effort. Particular care should, however, be taken not to regard the system as a generalised activity, but as a highly specialised means of ensuring the survival of important, but not necessarily unique, features of the natural environment. As such it needs the close attention of every conservation authority in the country. 